\title{
THE OCCURRENCE OF SIALOGLYCOLIPIDS IN BULL, BUFFALO AND GOAT SEMEN
}

\author{
Y. C. JAIN AND S. R. ANAND \\ National Dairy Research Institute, Karnal, India
}

(Received 22nd April 1974)

Poulos \& White (1974) demonstrated the presence of at least five separate glycolipid components in boar spermatozoa by thin-layer chromatography, and a similar number of glycolipids have been characterized by the same method in buffalo semen (Y. C. Jain and S. R. Anand, unpublished data), but no work has been done on the sialic acid-containing glycolipids called gangliosides. The latter are a group of glycosphingolipids characterized by the absence of phosphorus, and the presence of sialic acid, sugar (usually galactose and/or glucose), amino sugar (usually acetylgalactosamine) and ceramide, normally in the form of a complex composed of a long chain fatty acid and sphingosine. In this communication, the occurrence of sialoglycolipids, tentatively identified as gangliosides by thin-layer chromatography, in bull, buffalo and goat semen is described.

Semen was collected using an artificial vagina and, after pooling according to species, the spermatozoa were separated from the seminal plasma by centrifugation. The separated seminal plasma was taken to dryness under vacuum. Unless otherwise stated, all drying operations were carried out in a rotary flash evaporator at reduced pressure below $50^{\circ} \mathrm{C}$ and solvents were freshly distilled before use. Lipids were extracted from spermatozoa and plasma with chloroform:methanol $(2: 1, \mathrm{v} / \mathrm{v})$. The crude extract was washed with $1 / 5$ of its volume of water containing $0.37 \% \mathrm{KCl}$ (Folch, Lees \& Sloane-Stanley, $1957)$ and the mixture was allowed to separate into two phases on standing. The upper aqueous layer was removed and the lower layer was washed twice with a 0.1 vol. of the 'pure solvent upper phase' of the Folch system. The combined upper layers were concentrated to a small volume and dialysed against distilled water for $72 \mathrm{hr}$ at $5^{\circ} \mathrm{C}$. The non-dialysable portion was taken to dryness and the residue was extracted with chloroform: methanol $(1: 1, \mathrm{v} / \mathrm{v})$. The chloroform: methanol extract was filtered and the extractions were repeated twice more. The combined chloroform:methanol extracts were finally taken to dryness and stored under nitrogen in a frozen condition to prevent the loss of sialic acid due to spontaneous hydrolysis.

The phosphorus content was estimated according to the method described by Ahovcova \& Odavic (1969) and the total carbohydrate content by the orcinol method (Vassaur, 1948). For the estimation of sialic acid, the samples were hydrolysed with $0 \cdot 1 \mathrm{~N}-\mathrm{H}_{2} \mathrm{SO}_{4}$ at $80^{\circ} \mathrm{C}$ for $1 \mathrm{hr}$ and the amount was estimated by the thiobarbituric acid assay of Warren (1959). The hexosamines were determined in the hydrolysed samples $\left(1 \mathrm{~N}-\mathrm{HCl}\right.$ for $12 \mathrm{hr}$ at 100 to $105^{\circ} \mathrm{C}$ ) 
by the procedure of Cessi \& Piliego (1960). Sialolipids were identified on thinlayer chromatograms with orcinol and resorcinol spray reagents (Svennerholm, 1957). Visualization of different spots was obtained by spraying with $40 \%$ $\mathrm{H}_{2} \mathrm{SO}_{4}$ followed by charring. For quantification, the bands were delineated by iodine vapour, scraped and the sialic acid was estimated.

The sialic acid, total carbohydrate and hexosamine contents of sialoglycolipids in bull, buffalo and goat spermatozoa and seminal plasma were estimated and the values are reported in Table 1 . An estimation for phosphorus showed it to be absent in this fraction. The resolution of semen sialolipids on silica gel G-coated thin-layer plates was obtained using the solvent system chloroform: methanol:2.5 $\mathrm{N}-\mathrm{NH}_{4} \mathrm{OH}(60: 35: 8$, by vol.) as shown in Pl. 1, Fig. 1. Their pattern differed considerably from that of human brain gangliosides which were chromatographed simultaneously. Polysialo compounds were more prominent in human brain and they migrated largely to the lower half of the plate whereas the semen sialolipids had apparently more of the monosialo compounds giving many distinct bands in the upper half of the plate. The total

Table 1. Sialic acid, total carbohydrates and hexosamine content of bull, buffalo and goat semen sialoglycolipids

\begin{tabular}{l|rrr|crc}
\hline & \multicolumn{3}{|c|}{$\begin{array}{c}\text { Spermatozoa } \\
(\mathrm{mg} / 100 \mathrm{~g} \text { wet wt })\end{array}$} & \multicolumn{3}{c}{$\begin{array}{c}\text { Seminal plasma } \\
(\mathrm{mg} / 100 \mathrm{ml})\end{array}$} \\
& Bull & Buffalo & Goat & Bull & Buffalo & Goat \\
\hline Sialic acid & 1.31 & $4 \cdot 26$ & 2.96 & 0.20 & $0 \cdot 14$ & $0 \cdot 18$ \\
Total carbohydrates & 11.52 & 17.24 & 12.80 & 0.65 & 0.57 & 0.55 \\
Hexosamine & 2.50 & 3.63 & 0.66 & 0.23 & 0.21 & 0.17 \\
\hline
\end{tabular}

The values are averages of duplicates and are expressed in terms of $\mathrm{mg} / 100 \mathrm{~g}$ wet wt of spermatozoa and $\mathrm{mg} / 100 \mathrm{ml}$ seminal plasma.

number of resorcinol-positive spots was also greater in the semen sialolipids than in the human brain gangliosides (eight to ten in semen compared to six in human brain). In addition, the proportions in which sialic acid, total carbohydrates and hexosamines were present in human brain gangliosides and semen sialolipids was, however, achieved with solvent system propan-1-ol:water $(72: 28, v / v)$ which gave eight spots for sperm lipids and nine for seminal

\section{EXPLANATION OF PLATE 1}

Fig. 1. Thin-layer chromatography pattern of cattle and buffalo semen sialoglycolipids and human brain gangliosides. Solvent system-chloroform:methanol :2.5 N-ammonium hydroxide $(60: 35: 8$, by vol.). The plates, $5 / 10 \times 20 \mathrm{~cm}, 0.5 \mathrm{~mm}$ silica gel-G, were activated for $1 \mathrm{hr}$ at $110^{\circ} \mathrm{C}$. Visualization: $40 \% \mathrm{H}_{2} \mathrm{SO}_{4}$. CPGS, cattle seminal plasma gangliosides; CSGS, cattle sperm gangliosides; BPGS, buffalo seminal plasma gangliosides; BSGS, buffalo sperm gangliosides; HBGS, human brain gangliosides; $\mathrm{G}_{\mathrm{M} 1}$, monosialo ganglioside; $G_{D 1 a}$ and $G_{D 1 b}$, disialo ganglioside; $G_{T}$, trisialo ganglioside.

Fig. 2. Thin-layer chromatography pattern of cattle and buffalo semen sialoglycolipids and human brain gangliosides. Solvent system: propan-1-ol:water $(72: 28, \mathrm{v} / \mathrm{v})$. The plates, $5 / 10 \times 40 \mathrm{~cm}, 0.5 \mathrm{~mm}$ silica gel $\mathrm{G}$, were activated for $2 \mathrm{hr}$ at $110^{\circ} \mathrm{C}$, and one ascending run at room temperature for $18 \mathrm{hr}$. Visualization: resorcinol spray for CSGS, BPGS and BSGS, $40 \% \mathrm{H}_{2} \mathrm{SO}_{4}$ for $\mathrm{HBGS}$ and iodine vapours for CPGS. Abbreviations as in Fig. 1. In the left margin, band numbers are shown and in the right margin, tentative classes according to the Svennerholm system of classification are given (see Table 2). 
PIATE 1

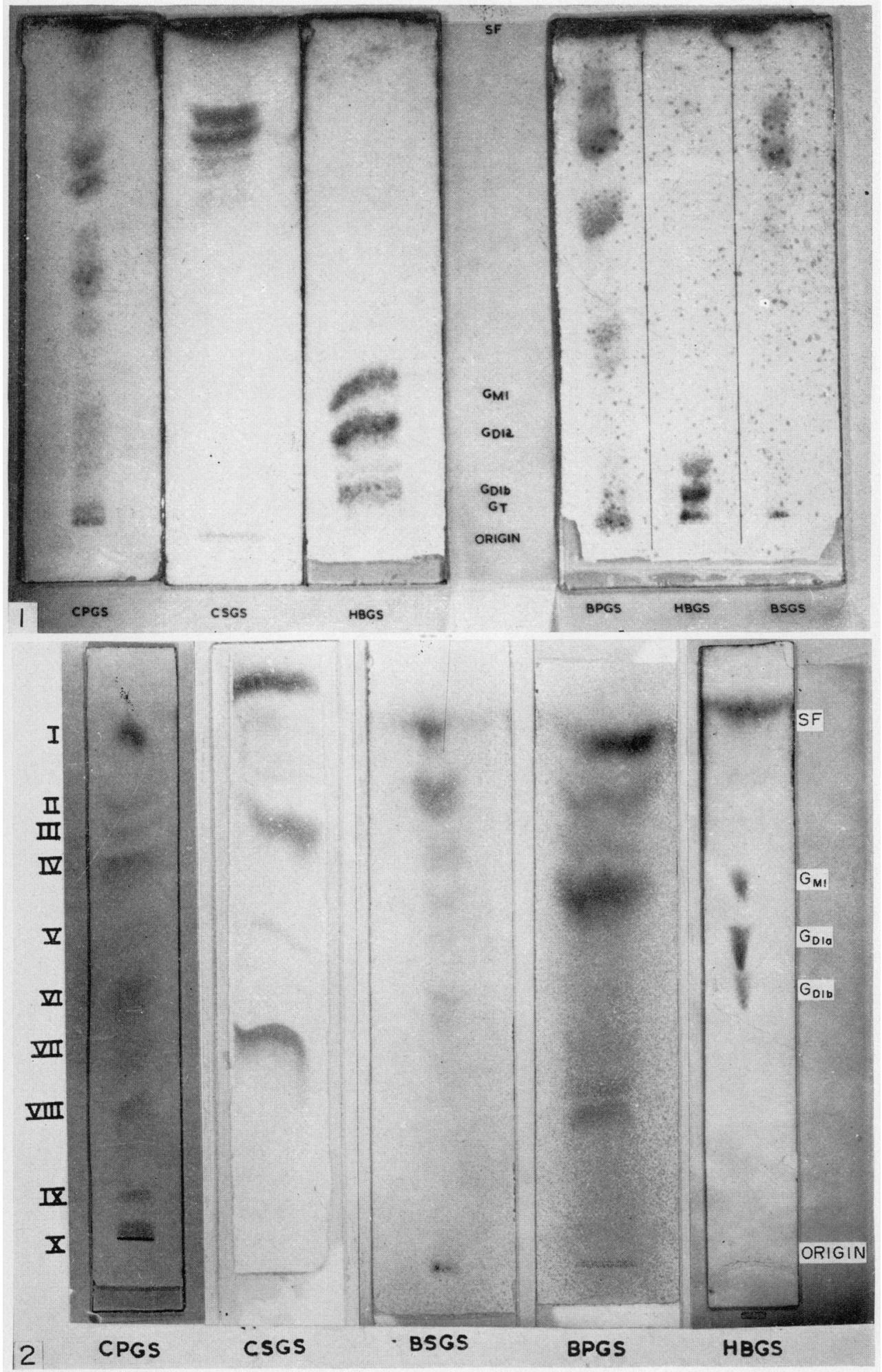

(Facing p. 130) 
plasma (P1. 1, Fig. 2). These were numbered (I to X) from solvent front to base. Six (I, II, IV, VII, VIII and X) were major fractions accounting for more than $80 \%$ of the sialic acid applied to the plate. A spot occasionally appeared between Spots III and IV which was a non-sialoglycolipid (globoside). It did not give the characteristic violet colour with resorcinol but turned golden yellow/orange when plates stained with resorcinol were sprayed with $\mathrm{H}_{2} \mathrm{SO}_{4}$ and charred at $160^{\circ}$. Based on their chromatographic mobility in relation to human brain gangliosides, semen sialoglycolipids have been tentatively identified as gangliosides (Table 2). The spermatozoa and seminal plasma of the three species gave similar respective chromatographic patterns but there were quantitative differences between the species. Qualitative and

Table 2. Differential analysis of semen sialoglycolipids as percentage of total sialic acid

\begin{tabular}{|c|c|c|c|c|c|c|c|}
\hline \multirow[b]{2}{*}{ Spot no. } & \multirow{2}{*}{$\begin{array}{c}\text { Tentative } \\
\text { identification }\end{array}$} & \multicolumn{3}{|c|}{ Spermatozoa } & \multicolumn{3}{|c|}{ Seminal plasma } \\
\hline & & Bull & Buffalo & Goat & Bull & Buffalo & Goat \\
\hline I & $\mathbf{X}$ & $10 \cdot 6$ & $9 \cdot 8$ & $9 \cdot 7$ & $5 \cdot 6$ & $7 \cdot 4$ & $10 \cdot 4$ \\
\hline II & $X_{1}$ & $7 \cdot 2$ & $10 \cdot 4$ & $9 \cdot 7$ & $5 \cdot 6$ & $6 \cdot 3$ & $9 \cdot 6$ \\
\hline III & & $4 \cdot 8$ & $6 \cdot 8$ & $3 \cdot 2$ & $6 \cdot 7$ & $5 \cdot 6$ & $5 \cdot 2$ \\
\hline IV & $\mathrm{G}_{\mathrm{M} 1}$ & $23 \cdot 8$ & $22 \cdot 2$ & 21.2 & $24 \cdot 2$ & 20.7 & $21 \cdot 2$ \\
\hline V & $G_{D 1 a}$ & $7 \cdot 0$ & $5 \cdot 2$ & 10.4 & $6 \cdot 5$ & $4 \cdot 2$ & $6 \cdot \overline{4}$ \\
\hline VI & $\mathrm{X}_{3}$ & $4 \cdot 2$ & $2 \cdot 6$ & $4 \cdot 4$ & $17 \cdot 4$ & $4 \cdot 6$ & $10 \cdot 0$ \\
\hline VII & $\mathrm{G}_{\mathrm{D} 1 \mathrm{~b}}$ & 16.8 & 16.4 & $14 \cdot 4$ & $7 \cdot 4$ & 14.4 & $10 \cdot 2$ \\
\hline VIII & $\mathrm{G}_{\mathrm{Tr}}$ & 16.4 & $18 \cdot 0$ & 18.6 & $8 \cdot 7$ & $19 \cdot 4$ & $10 \cdot \overline{4}$ \\
\hline IX & $x_{4}$ & - & & & $4 \cdot 4$ & $3 \cdot 2$ & $2 \cdot 4$ \\
\hline $\mathbf{X}$ & Origin & $9 \cdot 2$ & $8 \cdot 6$ & $8 \cdot 4$ & $13 \cdot 5$ & $14 \cdot 2$ & $14 \cdot 2$ \\
\hline
\end{tabular}

The identifications were according to the system of nomenclature and classification of Svennerholm (1957). $\mathrm{X}=$ unidentified.

quantitative differences also existed between the sialoglycolipids in the spermatozoa and the seminal plasma. The physiological rôle occupied by sialoglycolipids in the reproductive processes of bulls, buffaloes and goats remains to be explored.

The authors are grateful to the director, Dr D. Sundaresan, for encouragement and to the Indian Council of Agricultural Research, New Delhi, for providing a UNDP fellowship to one of us (Y.C.J.). A gift of human brain gangliosides from Sigma Chemical Company, U.S.A., is also gratefully acknowledged.

The paper is NDRI publication No. 74-38.

\section{REFERENCES}

Ahovcova, J. K. \& Odavic, R. (1969) A simple method for the quantitative analysis of phospholipids separated by thin-layer chromatography. 7. Chromatog. 40, 90-96.

Cessi, C. \& Piliego, F. (1960) The determination of amino sugars in the presence of amino acids and glucose. Biochem. 7. 77, 508-510.

Folch, J., Lees, M. \& Sloane-Stanley, G. H. (1957) A simple method for the isolation and purification of total lipids from animal tissues. 7 . biol. Chem. 226, 497-509.

PouLos, A. \& WHITE, I. G. (1974) The glycolipids of boar spermatozoa. F. Reprod. Fert. 36, 452. 
Svennerholm, L. (1957) Quantitative estimation of sialic acids. II. A colorimetric resorcinol-hydrochloric acid method. Biochim. biophys. Acta, 24, 604-611.

VAsseur, E. (1948) A spectrophotometric study on the orcinol reaction with carbohydrates. Acta chem. scand. 2, 693-701.

WARREN, L. (1959) The thiobarbituric acid assay of sialic acids. F. biol. Chem. 234, 1971-1975. 